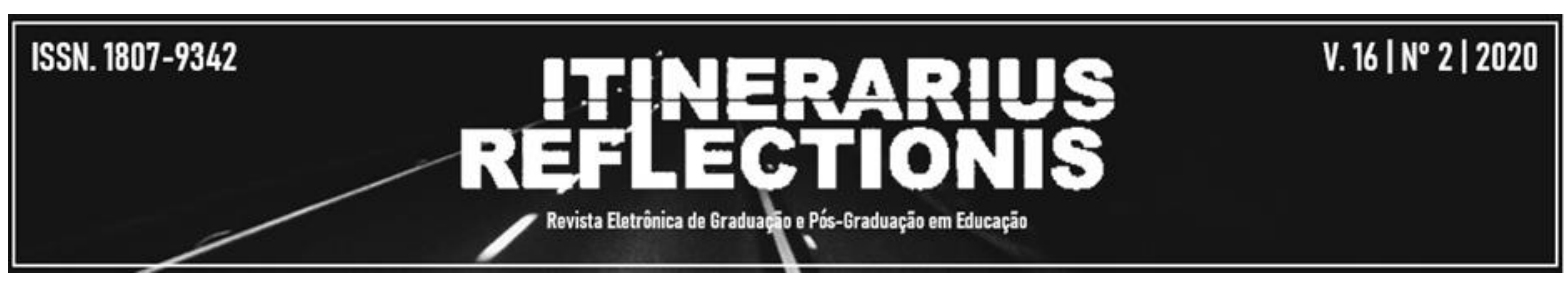

\title{
Funções e especificidades da escola pública nos processos inclusivos
}

\author{
Lilian Batista do Nascimento ${ }^{1}$ \\ Vanderlei Balbino da Costa ${ }^{2}$
}

\begin{abstract}
Resumo: O presente artigo tem como objetivo discutir de forma reflexiva sobre as funções e especificidades da escola pública, em uma perspectiva inclusiva. $\mathrm{O}$ problema de pesquisa enfatizado neste estudo gerou o seguinte questionamento: por que ainda se registra a falta de compreensão sobre as funções e especificidades da escola pública em relação aos processos inclusivos? A opção metodológica foi pela pesquisa qualitativa, apoiado em referenciais bibliográficos que deram suporte teórico para a realização do estudo. Os resultados sinalizaram que na escola pública, em uma perspectiva inclusiva, há uma falta de compreensão no que se refere à sua especificidade (que é garantir aos educandos uma formação cultural e científica, por meio da instrução, estabelecida nas relações pedagógicas definidas historicamente). Registra-se ainda incompreensão sobre a sua função (que é de garantir ao educando um saber sistematizado, com base no ensino). Assim, esta função acaba não se efetivando para os alunos com Necessidades Educativas Especiais (NEE), uma vez que a educação ainda não é um direito garantido para todos.
\end{abstract}

Palavras-chave: Funções e especificidades da escola pública. Relações pedagógicas. Inclusão escolar.

\section{Functions and specificities of the public school in inclusive processes}

\begin{abstract}
This article aims to discuss, in a reflective way, the functions and specificities of the public school, in an inclusive perspective. The research problem emphasized in this study generated the following question: why is there still a lack of understanding about the functions and specificities of the public school in relation to inclusive processes? The methodological option was the qualitative research, supported by bibliographic references that provided theoretical support for the accomplishment of the study. The results indicated that in the public school, in an inclusive perspective, there is a lack of understanding regarding its specificity (which is to guarantee to the students a cultural and scientific formation, through education, established in historically defined pedagogical relations). There can be also detected a misunderstanding concerning their role or function (which is to guarantee the student a systematized knowledge, based on teaching). Thus, this function does not become effective for students with special educational needs (SEN), since education is not yet a guaranteed right for all.
\end{abstract}

Keywords: Functions and specificities of the public school. Pedagogical relations. School inclusion.

\footnotetext{
${ }^{1}$ Universidade Federal de Goiás (UFG/ Regional Jataí) lilianascim@hotmail.com

${ }^{2}$ Universidade Federal de Goiás (UFG/ Regional Jataí) vanderleibalbino@gmail.com
} 


\section{INTRODUÇÃO}

O objetivo deste estudo reflexivo consistiu-se em discutir sobre as funções e especificidades da escola pública em uma perspectiva inclusiva, a fim de contribuir para a garantia de uma educação que abarque a formação humana, independente do gênero; raça; ou diferenças estabelecidas pelas condições sociais; físicas ou psicológicas do educando.

A perspectiva inclusiva a qual nos referimos, está pautada em legislações como: a Lei de Diretrizes e Base da Educação Nacional - LDBEN (BRASIL, 1996); A Política Nacional de Educação Especial em uma perspectiva inclusiva (BRASIL 2008); O Plano Nacional de Educação - PNE (BRASIL 2014); A Lei Brasileira de Inclusão - LBI (BRASIL 2015), dentre outras que abriram as portas para a diversidade no intuito de incluir todas as pessoas, com e sem deficiência, no espaço escolar.

$\mathrm{O}$ interesse em escrever a respeito desta temática surgiu durante a participação na disciplina denominada "Pensamento Educacional Brasileiro", ofertada pelo Programa de PósGraduação em Educação da Universidade Federal de Goiás, Regional Jataí - UFG/REJ. Diante disso, o problema de pesquisa apontado a partir dessas considerações, gerou o seguinte questionamento: por que no sistema educacional ainda se registra a falta de compreensão sobre as funções e especificidades da escola pública em relação aos processos inclusivos?

É sabido que na atualidade, há gestores públicos insensíveis/incompreensíveis a inclusão, propondo que as pessoas com deficiência sejam colocadas em salas especiais, separadas dos alunos considerados "normais", ou seja, retornando a ideia do velho paradigma de integração escolar. Frente a este contexto, aponta-se a importância deste estudo, visto que a educação, ainda não conseguiu garantir a todos os educandos esse direito social, como confirmado pelos dados da Pesquisa Anual por Amostra de Domicílios Contínua (PnadContínua), ao verificarmos que no Brasil, cerca de 53,4 milhões de pessoas de 25 anos ou mais não concluíram o ensino fundamental, o que representa $40 \%$ da população, e que mais da metade dessa população $(52,6 \%)$ não chegou a se formar no ensino médio, o que corresponde a 70,3 milhões de pessoas (IBGE, 2019).

Para tanto, a investigação se norteou também sobre as novas tendências pedagógicas presentes nas políticas educacionais aprovadas no Brasil a partir das conferências de Jomtien (UNESCO, 1990) e Salamanca (UNESCO, 1994), destinada a educação inclusiva 
que possibilite o desenvolvimento educacional de pessoas com Necessidades Educativas Especiais (NEE).

As reflexões teóricas deste artigo versam sobre as concepções de Saviani (2015), em vista de críticas apresentadas por Libâneo (2012) em relação às funções e especificidades da educação, numa perspectiva inclusiva.

A opção neste estudo foi pela pesquisa qualitativa, caracterizada por Lüdke e André (1986, p. 11) como aquela que "tem o ambiente natural como sua fonte direta dos dados e o pesquisador como seu principal instrumento". Este estudo apoiou-se também em referenciais bibliográficos que, segundo Severino (2016, p. 131) é aquele que "se realiza a partir do registro disponível, decorrente de pesquisas anteriores, em documentos impressos, como livros, artigos, teses, etc.”, possibilitando um novo olhar sobre o tema.

\section{FUNÇÕES DA ESCOLA PÚBLICA: ENSINAR OU ACOLHER?}

A educação nos revela uma história marcada por estigmas, estereótipos, preconceitos e discriminações contra aqueles que foram, estão e ainda são excluídos do direito à educação (GOFFMAN, 1988). Essas tentativas a nosso ver, devem ser no sentido de promover transformações no sistema de ensino, principalmente no que tange a educação inclusiva. Uma questão relevante é estabelecer uma definição sobre as funções e especificidades da escola pública e reconhecer se cabe a ela ensinar ou acolher os educandos com NEE, assim como a importância das relações pedagógicas proporcionadas por estas instituições.

O processo de inclusão teve como marco histórico a Conferência Mundial sobre Educação para Todos, também conhecida como Declaração de Jomtien (UNESCO, 1990), cujo intuito, segundo Libâneo (2012), era possibilitar o atendimento das pessoas com deficiência nas escolas públicas, visando o respeito às diferenças no processo de desenvolvimento.

Apesar dos esforços voltados para a inclusão, a fim de encontrar caminhos que favorecessem o desenvolvimento do educando com deficiência, esses movimentos esbarravam em relações pedagógicas que confundiam o ato de ensinar com o de acolher. Falamos em ensinar e acolher porque durante décadas as escolas caracterizadas como 
especiais tiveram esse papel. Exemplifica-se esse acolhimento nas ações especiais promovidas pelas APAE, Pestallozzis, dentre outras instituições que se prestavam a esse fim.

Partiu-se da premissa de que o termo conceitual é percebido como uma diferença, definido como deficiente ou excepcional. Em suas ponderações, Puppin (1999) afiança que o termo deficiência surgiu no século XIX, a partir do conceito de eficiência, utilizado no século XVIII. A terminologia deficiência tinha como objetivo classificar aquilo que era "improdutivo, negativo", passando então a ser denotado como fator de identidade humana. Por sua vez, Mazzotta (1982, citado por PUPPIN, 1999, p. 247), afirma que:

São considerados excepcionais os educandos que, em razão de desvios acentuados, de ordem física, intelectual, emocional ou sociocultural, apresentem necessidades educacionais que para serem adequadamente atendidas requerem auxílio ou serviços especiais de educação.

Em análise, as terminologias, excepcional ou deficiente, são designadas aos educandos com NEE, considerados inaptos, sem condições de se desenvolverem sozinhos. Neste contexto, pode-se apreender que essa condição de incapacidade caracteriza um educando improdutivo, desconsiderando o fator que lhe é próprio, o humano.

Por esse viés, infere-se que estando essa pessoa inserida em uma sociedade capitalista, a falta de habilidades e de produtividade, como elementos essenciais, poderia não garantir sua sobrevivência. Contudo, a interação entre educador e educando, com base em uma ação educativa considerada "normal", pode favorecer a formação humana. Neste sentido, Puppin (1999, p. 257) aponta que esta ação educativa de normalidade entre aluno/professor é determinada "pela essência humana do 'deficiente', entendida como base para o relacionamento".

Entretanto, visto que o processo de interação entre educador e educando se estabelece no âmbito escolar, Saviani (2015, p. 293), acentua que a especificidade da educação se refere:

[...] aos conhecimentos, idéias, conceitos, valores, atitudes, hábitos, símbolos sob o aspecto de elementos necessários à formação da humanidade em cada indivíduo singular, na forma de uma segunda natureza, que se produz, deliberada e intencionalmente, através de relações pedagógicas historicamente determinadas que se travam entre os homens.

Por essa vertente, Saviani (2015, p. 287) assinala que a função da educação é ensinar e sua especificidade é garantir aos educandos a instrução por meio das relações pedagógicas definidas historicamente, tendo em vista que o ato de aprender faz parte da 
natureza humana como um fator transformador afirmando que "a própria institucionalização do pedagógico através da escola é um indício da especificidade da educação”. Isto posto, na medida em que o educando entra em contato com os elementos culturais proporcionados pelo educador, o desenvolvimento e a aquisição de habilidades do educando se concretizam.

As habilidades das quais estamos falando se refere aos recursos didáticos acessíveis ao processo ensino/aprendizagem; as técnicas de ensino voltadas as especificidades de cada educando com necessidades educativas especiais; e, finalmente, aos procedimentos metodológicos capazes de promoverem à inclusão de todos, com e sem deficiência no espaço escolar.

Nesta mesma direção, Libâneo (2012) assegura que a ideia de que as especificidades da educação se estabelecem pela função da escola, de ensinar, para garantir ao aluno um saber sistematizado, uma formação "cultural e científica", numa visão integradora destinada às pessoas diferentes. Para o autor, a diferença humana já é uma condição concreta das situações inerentes à educação e aos educandos. É possível considerar que essas diferenças se referem às características físicas e psicológicas, e também, a forma de se conceber as informações.

Porém, é notório que a forma errônea de caracterizar a diferença humana, muitas vezes promovida em avaliações incoerentes, apresentado pelo trato pedagógico, priva o educando de oportunidades que possibilite seu desenvolvimento. Por essa ótica, encontra-se o professor que, por falta de conhecimento sobre a deficiência, não utiliza recursos necessários para favorecer o aprendizado, apoiando-se numa deficiência aparente apresentada por laudos médicos com diagnóstico inconsistente ou em dados equivocados, cuja consequência, acaba por desconsiderar a capacidade psicológica do educando para traçar seu plano de ensino.

À luz da literatura especializada, que enfatiza processos incoerentes nas avaliações, Lopes (2010), acentua que os alunos de inclusão não devem ser avaliados por critérios comparativos aos demais alunos. Essa avaliação deve ser feita de acordo com seu próprio desempenho, respeitando seus limites, ritmos e tempos de aprendizagem.

Ao abordar sobre a influência de prognósticos, Puppin (1999, p. 257) destaca no relato de uma professora, que "se tivesse lido o diagnóstico médico antes de iniciar o trabalho teria se influenciado e possivelmente não atingiria o objetivo". No entanto, quando ocorre a superação do prognóstico, Puppin (1999, p. 257) revela “[...] a descoberta de que há um horizonte de expectativas viáveis à situação específica de cada indivíduo, assumem 
frequentemente uma função propulsora da ação transformadora [...]”. Esta afirmação nos remete a ideia de que a escola tem como função, dispor elementos que assegurem a formação cultural e científica do aluno, independentemente de suas diferenças, sejam elas físicas, psicológicas ou sociais.

Nesse contexto, convêm apresentar o sentido denotativo das palavras "especificidade", "específico" e "função" a fim de favorecer uma melhor reflexão acerca do sentido real de cada uma delas. Para tanto, a referência das palavras abordadas por Ferreira (2001, p. 310) determina que:

$[\ldots]$

Especificidade: 1. Qualidade de específico; 2. Qualidade típica duma espécie". Específico: 1. De, ou próprio de espécie; 2 . Exclusivo, especial.

$[\ldots]$

Função: 1. Ação própria ou natural dum órgão, aparelho ou máquina; 2. Cargo, serviço, ofício; 3. Prática ou exercício de função; 4. Utilidade, serventia; 5. Posição, papel, atribuição.

Diante dessa premissa, compreende-se que os significados das palavras não se desvirtuaram do paradigma estabelecido por Libâneo (2012). A função da educação se estabelece pela ação atribuída ao seu papel, enquanto que a sua especificidade refere-se ao que lhe é próprio, específico. Deste modo, vale ressaltar que a opinião de Libâneo (2012) e Ferreira (2001) apontam para a ideia de que a função da escola é a ação atribuída a seu papel de forma própria, específica e que garanta ao aluno um saber cultural, científico por meio do ensino.

Todavia, apesar de os temas relacionados aos objetivos e as funções da escola terem sido amplamente discutidos pelo campo científico, como afiança Libâneo (2012), os resultados serviram apenas para calçar as mudanças nos planos governamentais, não resultando em transformações favoráveis ou substanciais à educação. Uma das tentativas, segundo o autor, diz respeito às incessantes disposições de recursos financeiros destinados ao ensino, por parte do governo, diante das múltiplas necessidades no âmbito educacional. Entretanto, é possível afirmar que estas mudanças eram mais voltadas para uma visão política do que propriamente dita de cunho pedagógico.

Cumpre-se assinalar que nas necessidades, incluía-se a falta de conhecimento sobre as questões pedagógicas que pudessem favorecer a educação inclusiva. O processo de globalização que borbulhou a partir dos anos de 1990 demonstrou que há veemente 
necessidade de investir na educação. Essa premissa é caracterizada nas conferências internacionais de educação em Jomtien (UNESCO, 1990) e Salamanca (UNESCO, 1994). Todavia, é profícuo se esclarecer que se por um lado houve avanços em relação ao aumento de matrículas de crianças nas escolas, por outro, esqueceram de investir na formação de professores para atuarem nas universidades, agora, abertas à diversidade de negros, indígenas, quilombolas e pessoas com deficiência, sujeitos desse estudo.

Ao discorrer sobre as questões pedagógicas de cunho humanistas, em uma perspectiva inclusiva, Libâneo (2012), deixa entrever que a função da escola é a de socialização. Além dessa afirmação, deixa clara sua posição crítica em relação a educação inclusiva, destacando que os direitos de igualdade, passaram a ser subordinados às diferenças. Estas diferenças podem ser identificadas em educandos com NEE, que apresentam dificuldades físicas; psicológicas; ou até mesmo de classes sociais. Portanto, a inclusão acaba por enfrentar barreiras que vão desde a dificuldade de acesso à escola, seja por falta de estrutura; de recursos pedagógicos; ou pela oposição promovida por barreiras atitudinais por parte de familiares dos alunos ditos normais.

É de grande valia retomar o entendimento de Libâneo (2012) sobre o sentido de igualdade, para compreendermos a função da escola numa perspectiva inclusiva que, segundo ele, isso só é possível mediante o desenvolvimento das capacidades intelectuais dos alunos. A simples confrontação das ideias apresentadas nos leva a concluir que os educandos considerados deficientes não se enquadram no sentido de igualdade, além de evidenciar que o ato de acolher, por parte da escola, se sobressai ao de ensinar. Essa analise, nos mostra que durante décadas a escola apenas segregou, integrou, enfim, acolheu aqueles que a sociedade os intitulava como anormais.

Ao se referir à igualdade no sistema educacional, apoiamos em Goffman (1988), quando denuncia que pessoas com deficiência têm sua identidade deteriorada porque sofre com estereótipos, discriminações e estigmas por aqueles considerados normais.

Nota-se que, desvirtuados da função da escola, esses educandos não se encontram alicerçados pelo direito à formação cultural e científica, diante das múltiplas dificuldades educacionais estabelecidas no sentido da deficiência, e dos desvios apresentados, considerados fatores que podem impossibilitar seu desenvolvimento educacional. Logo, esses fatores nos remetem a ideia de diferença humana, expressando também, o sentido de desigualdade e exclusão. O cenário educacional que se desenhou nas ultimas décadas do 
século XX, era caracterizado por desigualdade. Só para exemplificar até os anos de 1990, vivemos o período de integração, no qual os alunos com deficiência que não conseguissem sobressair na escola eram devolvidos para as salas especiais segregadas e a culpa não era do sistema, das escolas, nem ao menos dos professores (MANTOAN, 2003; SASSAKI, 2003; COSTA, 2012).

Entendemos que a escola, seja ela, pública ou privada em todos os níveis que atua em uma perspectiva inclusiva (BRASIL, 2008), deve e apoiar às estratégias e recursos pedagógicos que consiga solucionar os problemas sociais em consonância com as práticas educativas. Possivelmente assim, deixará de ser entendida como uma escola cuja tendência se denomina assistencialista, acolhedora, integrativa, mas sim, inclusiva, capaz de incluir a todos sem excluir e marginalizar. Frente ao exposto, Mazzotta (1982, citado por PUPPIN, 1999, p. 256), argumenta que todo recurso pedagógico apresenta "vantagens e desvantagens [...]. O recurso mais adequado será aquele que for mais compatível com as necessidades educacionais e a situação ambiental total de cada aluno". Contudo, não se pode eximir do fato da existência de algumas políticas educativas de inclusão direcionadas as escolas e das práticas pedagógicas. Uma delas diz respeito à política apresentada pelo Banco Mundial, cujo intuito era financiar as instituições favorecendo a educação, "preparando" a população para adentrar ao mercado de trabalho e erradicar a pobreza. Essa premissa é partilhada por Santos; Andrioli (1995), ao denunciarem o fenômeno da globalização que espraiou por todos os continentes a partir dos anos de 1990.

Em relação ao campo pedagógico, a aprendizagem e o desenvolvimento de habilidades, vistas numa perspectiva inclusiva, corre o risco de assumir características divergentes. Libâneo (2012, p. 20), afirma que "as escolas de países pobres assumem duas características pedagógicas: atendimento a necessidades mínimas de aprendizagem e espaço de convivência e acolhimento social", denominado por ele de "dualidade pedagógica". O sentido de escola dualista, cuja prioridade não se volta para a aprendizagem, se reduz ao espaço de acolhimento numa visão assistencialista, que por sua vez, dissocia da função destinada à escola.

Por essa vertente, Nóvoa (2009, citado por LIBÂNEO, 2012, p. 16-17), faz uma alerta ao classificar essa dualidade como uma "escola de duas velocidades", ao destacar que: 
outro lado, uma escola claramente centrada na aprendizagem e nas tecnologias, destinada a formar os filhos dos ricos.

A inferência de Nóvoa (2009, citado por LIBÂNEO, 2012), ao abordar que a escola de acolhimento social é para os pobres, nos remete ao entendimento de que pessoas com deficiência são pobres e ignorantes e, pessoas inteligentes são ricas, e ditas "normais". Tal conceito é evidentemente preconceituoso. Há aqui uma forma velada de isolamento e notoriamente excludente. Ou seja, se somos pobres, somos deficientes ou todos os deficientes são pobres.

Por esse viés, Libâneo (2012, p. 23) afiança que a função da escola pública é de "incluir populações excluídas ou marginalizadas pela lógica neoliberal, sem que os governos lhe disponibilizem investimentos suficientes, bons professores e inovações pedagógicas." Evidencia-se que a função da escola, para Libâneo (2012), é a de acolher, sem a preocupação de ensinar. Este conceito, na verdade, caracteriza uma forma de exclusão e de promoção da desigualdade social, além de conduzir ao conformismo as pessoas com NEE.

Partindo desse pressuposto, Puppin (1999, p. 255) destaca que:

\begin{abstract}
O isolamento mesmo que relativo imposto aos estigmatizados é a condenação do esforço de rompimento com a sua situação por parte de "normais" (que expressam explicita ou veladamente seu desagrado), e o apontar contínuo para as vantagens de uma aceitação, de um conformismo quanto ao lugar que a sociedade, de modo geral, reserva aos "deficientes" é por nós entendido como parte dessa moralidade que se emprega para manter as pessoas em seus lugares.
\end{abstract}

Outrossim, a aceitação do isolamento por parte da pessoa com deficiência acaba certificando, para o outro, sua condição como incapaz. Nota-se que a sociedade que exclui, mesmo que de forma velada, acaba por promover nessa pessoa, a desigualdade e o conformismo. É por essa vertente que se observa a necessidade de estabelecer o verdadeiro papel da escola pública, visto como socializador e inclusivo. Em virtude disso, entende-se que a função social da escola deve estar pautada num currículo comum escolar que contemple a formação humana visando a igualdade para que a justiça social prevaleça, possibilitando às Pessoas com Deficiência (PcD) a aquisição do conhecimento e desenvolvimento de suas habilidades intelectuais. Frente ao exposto, Libâneo (2012, p. 26) defende a ideia de que:

[...] não há justiça social sem conhecimento; não há cidadania se os alunos não aprenderem. Todas as crianças e jovens necessitam de uma base comum de conhecimentos, junto a ações que contenham o insucesso e o fracasso escolar. É claro que a escola pode, por um imperativo social e ético, cumprir algumas missões sociais e assistenciais (a escola convive com pobreza, fome, maus tratos, consumo de drogas, violência, etc.), mas isso não pode ser visto como sua tarefa e sua função 
primordial, mesmo porque a sociedade também precisa fazer sua parte nessas missões sociais e assistenciais.

De acordo com este raciocínio compreende-se que não há cidadania sem aprendizado. Esta só pode ser plenamente exercida à medida que o cidadão detém o conhecimento dos seus deveres e direitos, como membro de uma sociedade. Somente assim, poderia assumir a responsabilidade de seu fracasso escolar e social. Entretanto, Libâneo (2012), deixa claro que, apesar de poder, não cabe à escola a função de contribuir com questões atribuídas à sociedade, consideradas assistencialistas. Logo, ao analisarmos a questão em apreço, é possível considerar que cabe à escola a função de ensinar. Dessa forma, apenas os educandos que detém o conhecimento, com base no ensino, têm direito á justiça social e, só os alunos que aprendem, são considerados cidadãos.

Por esse viés, os dados apresentados na Declaração Mundial Sobre Educação para Todos, defende a ideia de que a educação é um elemento importante para estabelecer o desenvolvimento social e pessoal do ser humano, como podemos observar no artigo $1^{\circ}$ da World Conference on Education for All - WCEFA (UNESCO, 1990, citado por LIBÂNEO, 2012, p. 17) no qual afiança que:

\footnotetext{
Cada pessoa - criança, jovem ou adulto - deve estar em condições de aproveitar as oportunidades educativas voltadas para satisfazer suas necessidades básicas de aprendizagem. Essas necessidades compreendem tanto os instrumentos essenciais para a aprendizagem (como a leitura e a escrita, a expressão oral, o cálculo, a solução de problemas), quanto os conteúdos básicos da aprendizagem, (como conhecimentos, habilidades, valores e atitudes), necessários para que os seres humanos possam sobreviver desenvolver plenamente suas potencialidades, viver e trabalhar com dignidade, participar plenamente do desenvolvimento, melhorar a qualidade de vida, tomar decisões fundamentadas e continuar aprendendo.
}

Considerando os dados elencados no artigo $1^{\circ}$ da Declaração de Jomtien (UNESCO, 1990), bem como no artigo 17, da Declaração de Salamanca (UNESCO, 1994), como elementos essenciais, é possível inferir que os educandos, tanto os que apresentam NEE, quanto aos que erroneamente a sociedade intitulam como "normais", devem ter condições para aprender e desenvolver suas habilidades de forma a garantir sua sobrevivência no espaço escolar, que defendemos aqui ser verdadeiramente inclusivo (LIBÂNEO, 2012). Vale ressaltar que os referidos artigos nas duas conferências Jomtien e Salamanca, ao referir sobre o desenvolvimento pleno de suas potencialidades, parte do princípio de que o educando já possua habilidades que o permita a tomar decisões. 
Logo, pode-se concluir que não se pode potencializar um conhecimento que ainda não foi adquirido, sistematizado, (re) conhecido pelas escolas e principalmente pelos professores que ao invés de serem apenas inclusivos, devem ser mais inclusivistas. Nesse sentido é possível notar que a função da escola acaba não se efetivando para os educandos com NEE, uma vez que a educação ainda não é um direito garantido para todos.

\section{CONSIDERAÇÕES FINAIS}

O estudo acerca das funções e especificidades da escola pública nos processos inclusivos possibilitou compreender sobre as relações e influências sociais estabelecidas em espaços educativos inclusivos considerando que, de acordo com Saviani (2015), a escola necessariamente precisa, além de compreender suas especificidades, também respeitar as diferenças presentes em seus espaços sociais.

Com base na discussão sobre o tema, como objetivo proposto, os referenciais teóricos utilizados viabilizaram o entendimento do seguinte questionamento: por que no sistema educacional ainda se registra a falta de compreensão sobre as funções e especificidades das escolas, bem como dos professores em todos os níveis, principalmente quando o alvo é o processo inclusivo?

À luz da literatura, Bueno (1999), acentua que isso ocorre porque há no sistema educacional professores generalistas sem habilitação para atuar nas escolas quando registramos matrículas de alunos com Necessidades Educativas Especiais. Para a obtenção da resposta do problema levantado, foi possível partir de duas vertentes, a de ensinar/ incluir.

Ressaltamos aqui que ensinar em uma perspectiva inclusiva é mediar/promover/partilhar conhecimentos a partir daquilo que Tardif (2002), chama de "saberes experienciais". Quanto a perspectiva de ensino, compreende-se que é função da escola pública garantir ao aluno um saber sistematizado, com base no ensino. Ou seja, a função da escola pública é ensinar.

No que tange à especificidade da escola pública, lhe cabe garantir aos educandos uma formação cultural e científica, por meio da instrução estabelecida nas relações pedagógicas definidas historicamente. Por esse aspecto, para que se promova o desenvolvimento do educando, a escola pública numa perspectiva inclusiva, deve se atentar a alguns fatores considerados importantes, tais como: o despreparo do educador para lidar com 
o diferente, uma vez que em pleno século XXI, três décadas após a publicação da Lei de Diretrizes e Bases da Educação Nacional (BRASIL, 1996), ainda temos nas universidades cursos que formam professores, que não contém em suas grades disciplinas de educação especial (COSTA; LIMA; ROCHA, 2019). Soma-se a essa lacuna, a falta de materiais pedagógicos adaptados, que também inviabilizam a aquisição de conteúdo e, finalmente, o preconceito social, estereótipos e estigmas atribuídos as pessoas com NEE. A rejeição familiar, que não participa ativamente da trajetória escolar dos alunos com deficiência, bem como as múltiplas dificuldades inerentes à própria condição do educando com deficiência.

Estes fatores podem ser considerados como influenciadores negativos para o não desenvolvimento da pessoa com NEE. Os fatores negativos a que nos referimos se caracterizam no espaço escolar quando não há respeito às diferenças, quando o currículo não é adaptado às necessidades especificas de cada educando. Enfim, quando "normalizamos" todos, como se todos fossem iguais, apreendessem do mesmo jeito, da mesma forma, ao mesmo tempo.

Assim, partindo da premissa de que a escola, seja ela pública ou privada, tem a função de ensinar, ao considerarmos como exigência a necessidade da apresentação do desenvolvimento intelectual do educando com NEE, percebe-se que há uma disfunção deste aspecto, visto que, não se pode estabelecer uma garantia do ensino a esse educando sobre a aquisição do saber sistematizado. Por essa ótica, a função da escola inclusiva, que deveria ser de ensinar/partilhar/mediar saberes, passa a ser a de acolher, desvirtuando sua real função que é a de ensinar na e para a diversidade.

Diante das ponderações apontadas neste artigo de reflexão, ficam evidentes que o problema em relação a especificidade e função da escola, em uma perspectiva inclusiva, ainda precisa passar por processos de formação dos agentes que a compõem. A análise dos referenciais permitiu inferir que no sistema educacional a função de ensinar acaba não se efetivando, pois não se pode garantir ao educando com NEE um saber sistematizado por meio do ensino, já que este ensino, possivelmente, se encontra ladeado de dificuldades, considerando que ainda não há em grande parte dos cursos disciplinas de educação especial para habilitar os novos docentes que vão adentrar nas escolas. O trabalho pedagógico destinado à especificidade da escola em todos os níveis, é que deve lhe possibilitar a apreensão cultural, científica, o conhecimento globalizado, além da sua formação humana, de forma acolhedora, não fugindo da sua especificidade que é a de ensinar. 
Nesta analise não conclusiva, nossa crença é de que a inclusão nas escolas públicas se efetive. No entanto, para que isso ocorra é preciso que haja uma mudança atitudinal das partes envolvidas, dentro e fora da instituição escolar, assim como a utilização de trabalhos pedagógicos e políticas públicas adequadas ao ensino de pessoas com NEE. Vale ressaltar, que é por meio das relações constituídas entre as partes que se estabelece a diferença entre o ato de ensinar e acolher, de incluir ou excluir.

Portanto, em uma perspectiva inclusiva, é função da escola pública, diante das suas especificidades, por meio das relações pedagógicas, avaliar as condições mínimas apresentadas pelas pessoas com NEE, para estabelecer os instrumentos adequados ao seu desenvolvimento, a fim de possibilitar a aquisição do conhecimento e potencializar suas habilidades. Ao que se refere às habilidades dos educandos com NEEs, é profícuo acentuar que as Diretrizes Curriculares Nacionais, (BRASIL, 2001), bem como a Política Nacional de Educação Especial numa perspectiva inclusiva, (BRASIL, 2008), nos oferecem suportes pedagógicos que garante os processos inclusivos a estes educandos, uma vez que os mesmos necessitam de recursos didáticos adaptados as suas necessidades especificas.

\section{REFERÊNCIAS}

BRASIL. Conselho Nacional de Educação. Resolução CNE/CEB n 2, de 11 de setembro de 2001. Institui Diretrizes Nacionais para a Educação Especial na Educação Básica.

Disponível em: <http://portal.mec.gov.br/cne/arquivos/pdf/CEB0201.pdf>. Acesso em: 06 jul. 2019.

BRASIL. Lei de Diretrizes e Bases da Educação Nacional. Lei n 9394, 20 de dezembro de 1996.

BRASIL. Ministério da Educação. Política Nacional de Educação Especial na Perspectiva da Educação Inclusiva. Brasília, 2008. Disponível em:

<http://portal.mec.gov.br/arquivos/pdf/politicaeducespecial.pdf >. Acesso em: 16 de fev. 2020.

BRASIL. Presidência da República. Lei 13.146/2015, de 06 de julho de 2015. Institui a Lei Brasileira de Inclusão da Pessoa com Deficiência (Estatuto da Pessoa com Deficiência). Disponível em: <http://www.planalto.gov.br/ccivil_03/_ato2015-2018/2015/lei/113146.htm>. Acesso em: 08 de jul. 2019.

BRASIL. Presidência da República. Lei no 13.005, de 25 de junho de 2014. Aprova o Plano Nacional de Educação - PNE e dá outras providências. Disponível em: <http://www.planalto.gov.br/ccivil_03/_Ato2011-2014/2014/Lei/L13005.htm>. Acesso em: 05 mai. 2015. 
BUENO, José Geraldo Silveira. Crianças com necessidades educativas especiais, política educacional e a formação de professores: generalistas ou especialistas. Revista Brasileira de Educação Especial. UNESP Marilia SP. V3. p 7 - 25. 1999.

COSTA, Vanderlei Balbino. Inclusão Escolar do Deficiente Visual no Ensino Regular. Jundiaí, Paco Editorial: 2012.

COSTA, Vanderlei Balbino; LIMA, Adrielle Martins; ROCHA, Leonor Paniago. A (de)formação da formação inicial dos professores na perspectiva da escola inclusiva. In: ENCONTRO IBERO-AMERICANO DE EDUCAÇÃO, 14, 2019, Araraquara. Anais do [...]. São Paulo: UNESP, 2019.

FERREIRA, Aurélio Buarque de Holanda. Mini Aurélio Século XXI. $5^{\text {a }}$ edição Revista e Ampliada. Rio de Janeiro. Editora Nova Fronteira S.A, 2001.

GOFFMAN, E. Estigma: notas sobre a manipulação da identidade deteriorada. 4. ed. Rio de Janeiro: Guanabara, 1988.

IBGE, Instituto Brasileiro de Geografia e Estatística. PNAD Contínua 2018: educação avança no país, mas desigualdades raciais e por região persistem. Agência IBGE notícias, 2019. Disponível em: <https://agenciadenoticias.ibge.gov.br/agencia-sala-de-imprensa/2013agencia-de-noticias/releases/24857-pnad-continua-2018-educacao-avanca-no-pais-masdesigualdades-raciais-e-por-regiao-persistem>. Acesso em: 24 fev. 2020.

LIBÂNEO, José Carlos. O dualismo perverso da escola pública brasileira: escola do conhecimento para os ricos, escola do acolhimento social para os pobres. Educação e Pesquisa, São Paulo, v. 38, n. 1, p. 13-28, 2012.

LOPES, Noêmia. 24 respostas para as principais dúvidas sobre inclusão. 2010. Disponível em: <http://gestaoescolar.abril.com.br/formacao/24-respostas-principais-duvidas-inclusao759360.shtml>. Acesso em: 16 abr. 2016.

LÜDKE, Menga; ANDRÉ, Marli E. D. A. Pesquisa em educação: abordagens qualitativas. São Paulo: EPU, 1986.

MANTOAN, Maria Tereza Egler. Inclusão escolar: O que é? Por quê? Como fazer? São Paulo: Moderna, 2003.

PUPPIN, Andrea Brandão. Da atualidade de Goffman para a análise de casos de interação social: deficientes, educação e estigma. Revista brasileira Estudos pedagógicos, Brasília, v. 80, n. 195, p. 244-261, maio/ago. 1999. Disponível em: $<$ https://edisciplinas.usp.br/pluginfile.php/212950/mod_resource/content/2/Puppin\%20\%20Estigma\%20e\%20deficiencia\%20fisica.pdf>. Acesso em: 30 dez. 2018.

SANTOS, Robinson. ANDRIOLI, Antônio Inácio. Educação globalização e neoliberalismo: $O$ debate precisa continuar. Disponível em: <https://www.andrioli.com.br/index.php/artigos/63-educacao-globalizacao-eneoliberalismo-o-debate-precisa-continuar>. Acesso em: 23 out. 2019 
SASSAKI, Romeu. Como chamar as pessoas que têm deficiência? In: Vida Independente: história, movimento, liderança, conceito, filosofia e fundamentos. São Paulo: RNR, 2003, p. 12-16.

SAVIANI, Demerval. Sobre a Natureza e Especificidade da Educação. Germinal: Marxismo e Educação em Debate. Salvador, v. 7, n. 1, p. 286-293, jun. 2015. Disponível em: $<$ https://portalseer.ufba.br/index.php/revistagerminal/article/view/13575/9519>. Acesso em: 30 dez. 2018.

SEVERINO, Antônio Joaquim. Metodologia do Trabalho Científico. 24.ed. rev. e atual. São Paulo: Cortez, 2016.

TARDIF, Maurice. Saberes Docentes e Formação Profissional. $2^{\circ}$ edição. Editora vozes. Petrópolis, rio de janeiro 2002.

UNESCO. Declaração Mundial sobre Educação para Todos: satisfação das necessidades básicas de aprendizagem. UNESCO: Jomtiem, 1990.

UNESCO. Declaração de Salamanca de princípios, política e prática para as necessidades educativas especiais. Coordenadoria Nacional para a Integração da Pessoa Portadora de Deficiência (CORDE). Brasília: 1994. Disponível em: <http://portal.mec.gov.br/seesp/arquivos/pdf/salamanca.pdf >. Acesso em: 20 jul. 2018. 